\title{
Optimization of Ionic Polymer Metal Composite Fabrication via Chemical Electroless Plating Method; Actuation Application Study
}

\author{
Matin Sadat Saneei Mousavia,* (D), Faranak Manteghia, Mohammadreza Kolahdouz
}

a Department of Chemistry, Iran University of Science and Technology, Tehran, Iran

b School of Electrical and Computer Engineering, University of Tehran, Tehran, Iran

\begin{tabular}{|c|c|}
\hline ART ICLE INFO & A B S T RACT \\
\hline $\begin{array}{l}\text { Received: } 14 \text { October } 2019 \\
\text { Revised: } 07 \text { December } 2019 \\
\text { Accepted: } 25 \text { December } 2019 \\
\text { Available online: } 28 \text { December } 2019 \\
\text { K E Y W O R D S } \\
\text { Ionic polymer metal composite (IPMC) } \\
\text { Electroless plating method } \\
\text { Actuating application }\end{array}$ & $\begin{array}{l}\text { In this study, ionic polymer metal composite was fabricated using the } \\
\text { optimized chemical electroless plating (CEP) method. Bath ultra- } \\
\text { sonication was employed to deposit the platinum ions on the nafion } \\
\text { sheet which decreased the time of deposition from } 24 \mathrm{~h} \text { to } 3 \mathrm{~h} \text {. } \\
\text { Morphology of the fabricated ionic polymer metal composite (IPMC) was } \\
\text { characterized using the atomic force microscopy (AFM) and field } \\
\text { emission scanning electron microscopy (FESEM). A smooth platinum } \\
\text { layer with the thickness of about } 1 \mu \text { m was deposited on the nafion sheet } \\
\text { after one step deposition. Strain analysis also revealed high quality } \\
\text { electrode deposition on the nafion sheet. Inductively coupled plasma } \\
\text { (ICP) spectroscopy was utilized to measure the quantitative deposition } \\
\text { of Pt ions on the nafion sheet through sonication process. } 97.4 \% \text { of the } \\
\text { Pt ions in the solution were deposited on the nafion using the optimized } \\
\text { CEP process. Voltage-angle and force-voltage characterizations were } \\
\text { also employed to assess the actuation application of the fabricated IPMC. }\end{array}$ \\
\hline
\end{tabular}

G R A P H I C A L A B S T RACT

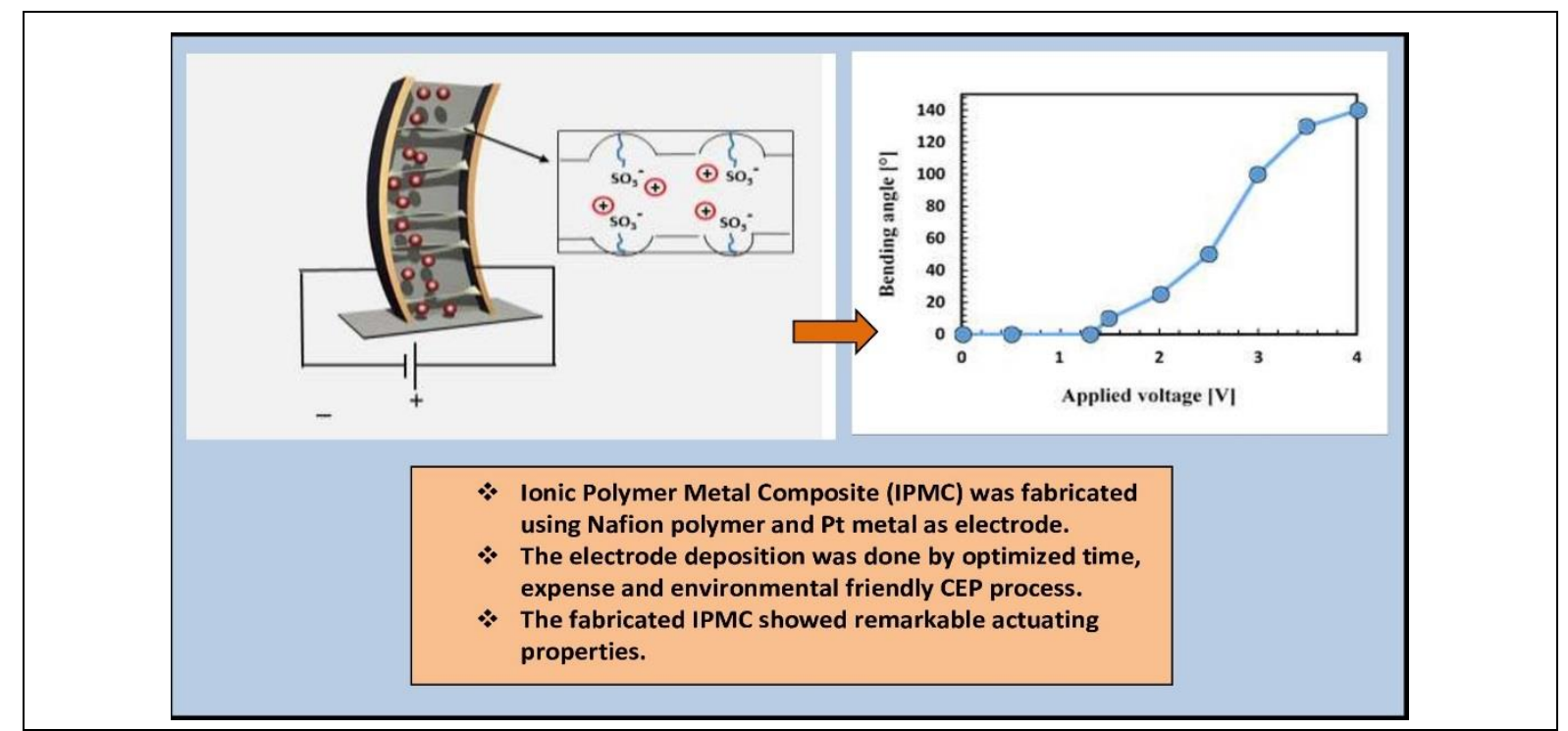

*Corresponding author's E-mail address: m_saneei@alumni.iust.ac.ir 


\section{Introduction}

Electroactive polymers (EAPs) are representatives of a new category of organic materials with relatively high conductive properties. Conductivity in these field of materials can be a great property to be used as functioning parts in many devices and can also be controlled by modifying their chemical and physical structure [1]. This conductivity, such as metals and semiconductors, is based on the charge mobility along with their backbone of the polymer chain which is considered as electronic structure [2-5]. Ionic polymer metal composite (IPMC) is a smart EAP which has demonstrated a large displacement with even less than $5 \mathrm{~V}$ driving potential. In particular, IPMC is a bending actuator suitable for applications where the source power is low. The bending deflection can be very large and could even extend beyond $90^{\circ}$ according to its trimmed shape. Therefore, the IPMC actuator possesses both actuation figures of merit together; large deflection and low extinction voltage [6]. IPMCs have been used as actuators in different fields such as biomechanical and biomedical applications (artificial muscles and drug delivery systems) [7-9], robotics and MEMS (transducers and sensors) [10-15], as well as the aerospace and vehicles industry [16-17]. Using nafion-based IPMC in biomedical field is of concern due to biocompatibility of both nafion and IPMC [1821].

Manufacturing IPMC starts with manipulating an ion exchange ionic polymer. The term of "ion exchange polymers" refers to polymers designed to selectively exchange ions of a single charge with their own incipient ions. They are often constructed from polymers consisting of fixed covalent ionic groups such as perfluorinated alkenes with short side chains, terminated either by ionic groups (typically sulfonate or carboxylate $\left(\mathrm{SO}_{3}{ }^{-}\right.$or $\left.\mathrm{COO}^{-}\right)$for cation exchange or by ammonium cations for anion exchange [22].
Nafion, as a sulfonated tetrafluoroethylenebased fluoropolymer, terminated by sulfonate groups onto the backbone, has drawn attentions as a cation exchanger membrane. In perfluorinated sulfonic acid polymers, there are relatively few fixed ionic groups. These groups are located at the end of the side-chains to give themselves a position in their preferred orientation to some extent. Therefore, they can create hydrophilic channels, also known as cluster networks. The $\mathrm{H}^{+}$ions of sulfonate can be traded with small cations such as $\mathrm{Na}^{+}$and $\mathrm{Li}^{+}$with the ability to move through the membrane within hydrated conditions in an electrical field [23].

To fabricate IPMC, as a general method, metallic electrodes should get deposited on the nafion polymer. Nafion polymer has a sort of internal channel in its membrane that lets the ions migrate between anode and cathode under a certain applied voltage [24]. Two main methods have been previously used to deposit metal layers on the nafion. First, the chemical electroless plating (CEP) process which involves chemical reactions; and second, physical sputtering (PS) metal deposition that has been studied in recent years and mainly involves the sputtering of chosen metals through a vacuum environment [25]. In the CEP method, as the more efficient one, the pretreated nafion is immersed in a metal complex which usually consists of Pt. As a noble metal, Pt is highly suitable to be used as the electrode [26]. Other metals (or conducting materials), are also successfully used, including palladium, silver, gold, carbon, graphene and nanotubes. The deposited ions on the nafion will then be converted to a metal layer by a reductant such as sodium borohydride [26]. This method usually prepares high quality electrode on nafion; however, it is time consuming since the required time for ion deposition and reduction may last from hours to days. In previous studies, the pretreated nafion sheet was kept in the metal complex solution for 
about one night. The additional steps of reduction with hydroxylamine and hydrazine solutions were also carried out which made the procedure even more time consuming and expensive [27]. The additional process was mainly executed to enhance the surface electrode quality. Herein, we have developed the CEP method with optimized and modified process times by using ultra sonication of the Pt complex solution while pretreated nafion is immersed. In fact, by using bath-ultra sonication, more $\mathrm{Pt}$ ions interact with nafion surface and hence the deposition takes place faster but with the same quality. The proposed flow has resulted in high quality metal electrode after reducing the metal ions without needing any additional reduction steps. Removing the use of extra materials for reduction with amine groups not only decreased the time and expense of the process but was also a great help to environment since the materials with amine groups are not safe for the environment. Finally, the efficient IPMC underwent a process to be tested for actuation applications.

\section{Experimental}

\section{Materials and methods}

The Nafion 115 sheet was provided from ION Power, GmbH. Hydrochloric acid and lithium chloride were prepared from Merck Millipore. Tetra amine platinum (II) chloride $\left(\mathrm{Pt}\left(\mathrm{NH}_{3}\right)_{4} \mathrm{Cl}_{2}\right)$ and sodium borohydride $\left(\mathrm{NaBH}_{4}\right)$ were purchased from Sigma Aldrich. A nafion sheet with the thickness of 127 microns was first cut in $15 \times 3 \mathrm{~mm}^{2}$ pieces.

\section{Optimized CEP procedure}

To fabricate the IPMC via the chemical route, both sides of the nafion sheet were primarily roughened by oxygen plasma to create active sites that achieve better adhesion of metal to the surface. Then the roughened nafion was boiled in diluted hydrochloric acid (2N) for $30 \mathrm{~min}$ in order to detach any impurities from the membrane. The membrane was then boiled in deionized water for $30 \mathrm{~min}$ to remove any acid from the surfaces.

Adsorption of the Pt ions acting as the metal electrode on the nafion surface was conducted as noted in previous studies [14], albeit with an optimization. As mentioned in the literature [22], the nafion sheet should be immersed in the aqueous solution of $\mathrm{Pt}$ complex $\left(\mathrm{Pt}\left(\mathrm{NH}_{3}\right)_{4} \mathrm{Cl}_{2}\right)$ with the proper ratio (3 $\mathrm{mg}$ of Pt per $\mathrm{cm}^{2}$ ) preferably for one night. The $\mathrm{Pt}$ ions should then be reduced to $\mathrm{Pt}$ layers by adding a sodium borohydride solution every $30 \mathrm{~min}$, making the whole process very time consuming. Herein, the nafion sheet was immersed and sonicated in the solution of tetra amine platinum (II) chloride ( $\mathrm{Pt}\left(\mathrm{NH}_{3}\right)_{4} \mathrm{Cl}_{2}, 10 \mathrm{mM}$ ) for only $3 \mathrm{~h}$ in an ultrasonic bath (100 watt). Sonication helped the adsorbing process to be done in a shorter time. To reduce the Pt ions, the nafion sheet was immersed in the aqueous solution of $\mathrm{NaBH}_{4}(6 \mathrm{mM})$ while rising the temperature from $40{ }^{\circ} \mathrm{C}$ to $60{ }^{\circ} \mathrm{C}$ for $2 \mathrm{~h}$. The sudden reduction of $\mathrm{Pt}$ ions in this warm reductant occurred without needing any necessary additional reduction steps by using other reductants with amine groups. Our time, expense efficient and environment friendly CEP approach produced a high quality Pt layer on the nafion, with the surface resistivity of about $0.2 \mathrm{ohm} / \mathrm{mm}^{2}$ on both sides. The final IPMC was obtained by trimming the membrane from all sides to avoid any direct connection (short circuit) between two electrodes.

\section{Ion exchange procedure}

As the final step, the prepared IPMC was kept in the stirring solution of $\mathrm{LiCl}(1 \mathrm{M})$ for 4 h. This process resulted in replacing the $\mathrm{H}^{+}$ ions attached to the sulfonate groups with small ions of $\mathrm{Li}^{+}$. In fact, the mobility of $\mathrm{Li}^{+}$is much higher than $\mathrm{H}^{+}$which results in faster 
and easier migration of them toward the cathode in an applied electrical field.

\section{Results and discussions}

\section{Morphological and microstructure analysis}

The key step in preparing the IPMC, is the pretreatment of the membrane. For example, surface roughening, which was initially proposed and adopted for the purpose of eliminating the issue of the electrode peeling off. Nafion surface roughening enlarged the interfacial area between the membrane and the electrode while forming penetrated electrodes [28]. An atomic force microscopy (AFM) analysis of the nafion surface after $\mathrm{O}_{2}$ plasma (Figure 1a) and sandblasting treatment followed by $\mathrm{O}_{2}$ plasma (Figure $1 \mathrm{~b}$ ). As it can be seen in Figure 1, oxygen atoms could uniformly roughen the nafion surface with the surface RMS roughness of $131.58 \mathrm{~nm}$. In other words, it could successfully prepare uniform active sites for the penetration and deposition of Pt ions on the nafion surface via the chemical route. Although sandblasting technique is a necessary step in the physical methods, it may produce less uniform sites with a surface roughness of $499.90 \mathrm{~nm}$. The sheet resistance of IPMC's electrodes was less than $0.5 \mathrm{ohms} / \mathrm{mm}^{2}$ right after synthesis. The low surface resistance implies successful deposition of metals in optimized CEP method. In this method, Pt particles penetrate into the swelled nafion with a diffusion coefficient of $5.2 \times 10^{-7} \mathrm{~cm}^{2} / \mathrm{s}$ while the amount of penetration depends on the time of process and concentration of the Pt complex [26]. Figure 1c illustrates the AFM images of the surface of the prepared IPMC after being immersed in water for the ion exchange step. As the AFM images display, the surface of the IPMC prepared via optimized CEP route shows a monotone and smooth deposition with a RMS roughness of $1.07 \mu \mathrm{m}$.

Figure $2\left(a\right.$ and $b$ ) shows SEM images $\left(45^{\circ}\right)$ of single and double deposition by optimized CEP method on nafion sheet respectively. The thickness of the deposited layer of electrode was intended to be approximately $1 \mu \mathrm{m}$ in the single deposition and $4 \mu \mathrm{m}$ for double deposition. The thicker the electrode is the better voltage bias at higher deflections and hence the better actuation application is achieved. As it is consistent with the AFM images, the deposited layers in both single and double deposition are smooth and uniform.

Figure 1. The morphology of the nafion sheet after a) 5 min $\mathrm{O}_{2}$ plasma and b) sandblasting followed by 5 min $\mathrm{O}_{2}$ plasma, c) IPMC surface prepared by optimized CEP method after immersing it in water for the ion exchange step
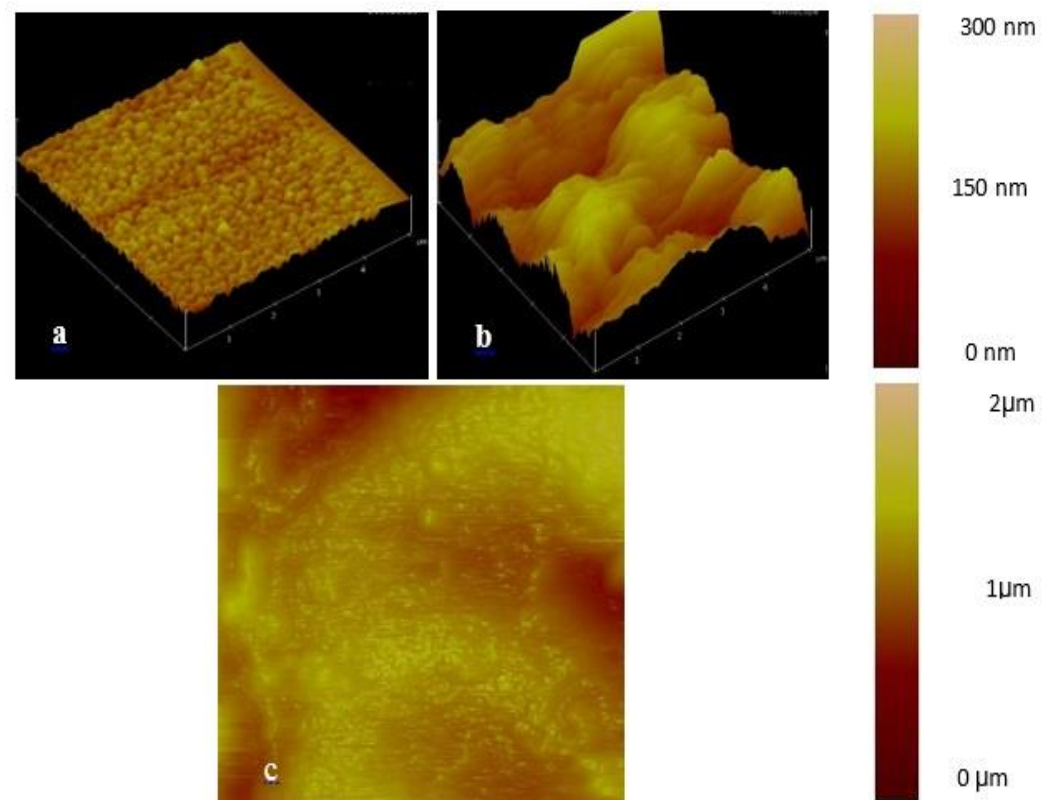
Figure 2. SEM images of prepared IPMC by optimized CEP method (a) single deposition double deposition, (c) optical microscope image of IPMC
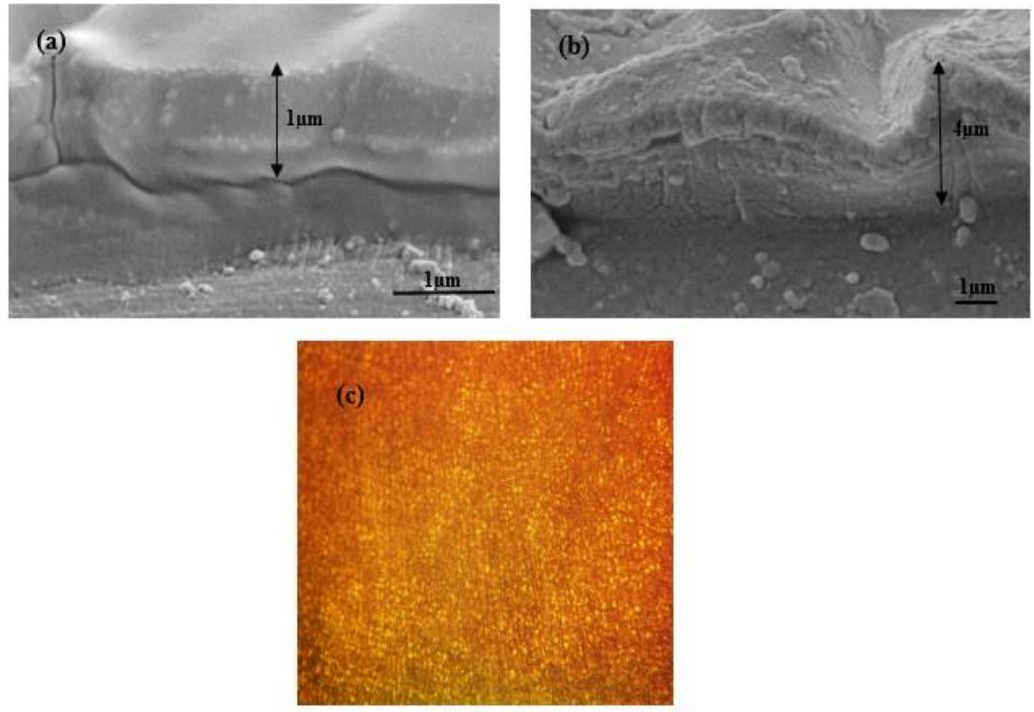

Figure 3. $\log ($ Resistance $(\Omega)$ ) vs strain (\%) for IPMC obtained by optimized CEP method

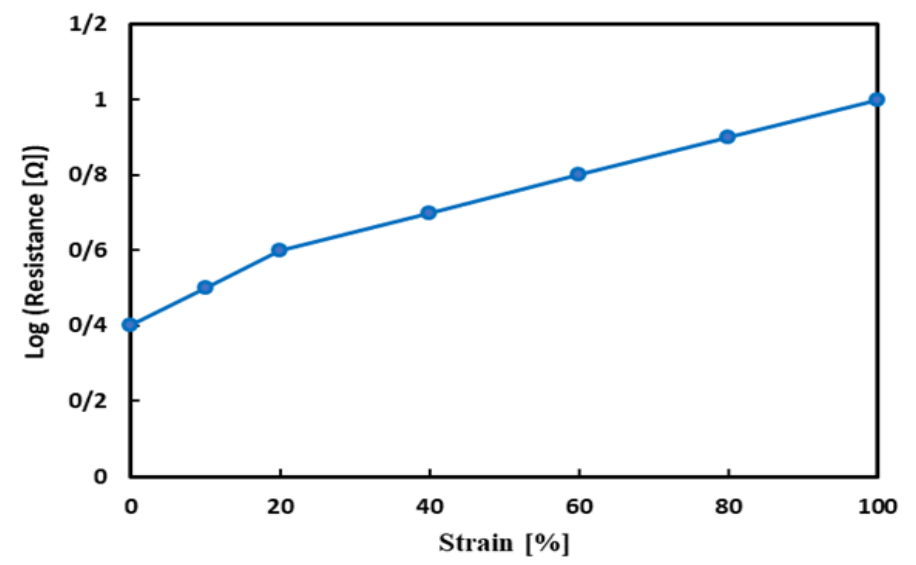

In addition, the more the deposition takes place, less cracked electrodes are obtained. Figure 2c also shows the optical microscope image of the as prepared IPMC after single step deposition which shows smooth layers of Pt electrode.

To acquire a better evaluation of the quality of the electrode, IPMC went under a strain analysis. To do so, the nafion polymer was cut in dimensions of $4 \mathrm{~cm} \times 0.5 \mathrm{~cm} .1 \mathrm{~cm}$ from each side was left without electrode for the attachment to measurement tools and so electrodes were deposited on the $2 \mathrm{~cm}$ in the middle. A resistance measurement was performed on the electrodes as the stress tests were carried out using a Universal Testing Machine (GEOTECH). Figure 3 shows the comparison of the electrode resistance vs. the strain on these samples. As it can be seen in this figure, the IPMC obtained by optimized CEP method experienced small changes of surface resistance while being stretched. Surface resistance started from $2.5 \Omega$ in $0 \%$ strain and reached to $10 \Omega$ after stretching to $100 \%$. This implies an excellent metal electrode adhesion to nafion with the quality being so high that the surface resistance stayed below $10 \Omega$ even under a $100 \%$ strain.

\section{Pt ions deposition measurement}

To understand whether or not the whole Pt ions in the solution were deposited on the nafion sheet through the sonication process, Pt atoms of the deposited layer on the IPMC sample were quantitatively measured using the inductively coupled plasma (ICP) spectroscopy. To do so, a sample of IPMC with 
the dimensions of $1.5 \mathrm{~cm} \times 0.5 \mathrm{~cm}$ was placed in the solution of $\mathrm{HCl} / \mathrm{HNO}_{3}(3: 1)$ for $5 \mathrm{~h}$ so that the Pt atoms from the deposited layer got dissolved in the aqua regia. Figure 4 shows the Pt analysis by absorbance intensity vs. ions concentration considering $\mathrm{Pt}$ standard calibration curve. As it was maintained from the curve, Pt ions concentration was calculated to be $115 \mathrm{ppm}$ which was so close to what it was expected to be (112 ppm) according to theoretical calculations. The $2.6 \%$ error may refer to instrumental or human error through the deposition process.

\section{Voltage-angle characterization}

IPMC is an active actuator with a large deformation at the presence of a low applied voltage. Actuation performance of the IPMC actuator is resulted solely from the motion of the lithium cations through the nafion membrane caused by the applied voltage across the sheet. Upon the application of an electric field, cations that are mobile, migrate towards the cathode. Accumulation of ions near an electrode results in an imbalance in volume within the samples and thus, a bending deformation occurs. IPMCs containing higher concentration of ionic liquid exhibited more capacitor-like behavior which leads to a larger electromechanical response. $\mathrm{Li}$ ion was used at the present work for the ion exchange process, causing a large and fast bending of IPMC due to its small size [29]. The fast response of the IPMC also inhibited it to display any back relaxation which usually occurs with larger ions [30].

Figure 5 a illustrates the schematic of the setup carried out for measuring the angle of bending IPMC vs. applied voltage. IPMC strip was placed between two handles of a clip. Each handle was then linked to a power supply to apply the positive and negative voltage to the IPMC. The angle of bending was then measured. Figure $5 b$ shows the angle of bending vs. the applied voltages at $1 \mathrm{~Hz}$ frequency after being immersed in an aqueous solution of $\mathrm{Li}^{+} 1 \mathrm{M}$ for $4 \mathrm{~h}$. As it can be seen in this figure, IPMC starts bending from a low threshold voltage of $1.3 \mathrm{~V}$ and bends up to about $140^{\circ}$ by applying only $4 \mathrm{~V}$. This implies the remarkable actuation application of the prepared IPMC in any device that needs a low voltage actuator with high bending reaction.

\section{Force-voltage characterization}

To evaluate the output force of the IPMC, a measurement setup consisting of a load cell and a power supply (Figure 6a) was established. The IPMC strip was placed in a straight position with zero-degree deflection on the load cell; meanwhile the load cell's force monitor displayed the applied force of the IPMC to the load cell ( $\mathrm{mN}$ ) while being actuated in the electrical field.

Figure 4. Absorbance intensity vs. Pt concentration curve derived by ICP spectroscopy

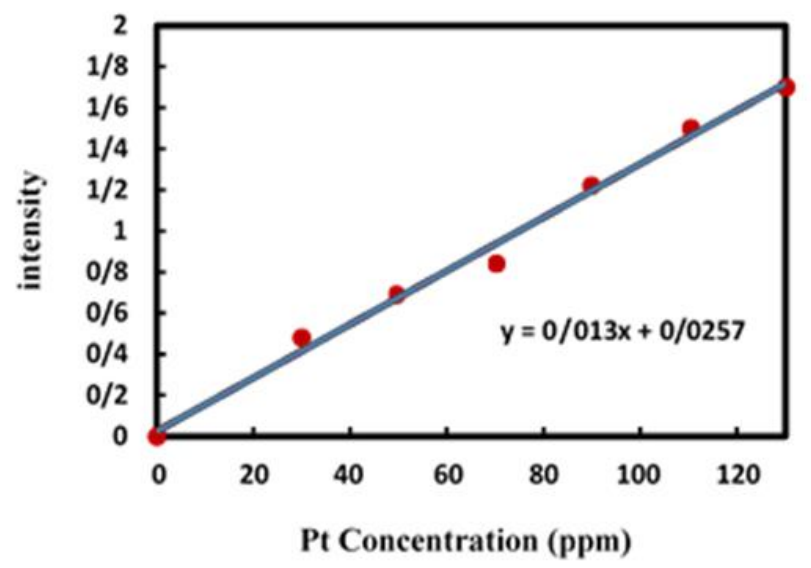


Figure 5. (a)

Schematic of the bending angle measurement set up, (b) bending angle vs. the applied voltage for the IPMC prepared by optimized CEP method

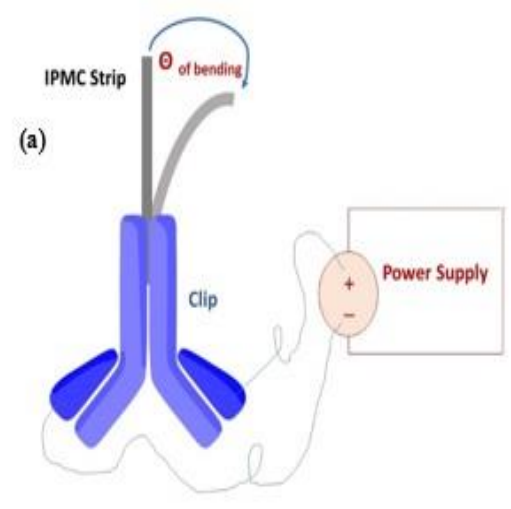

(a)

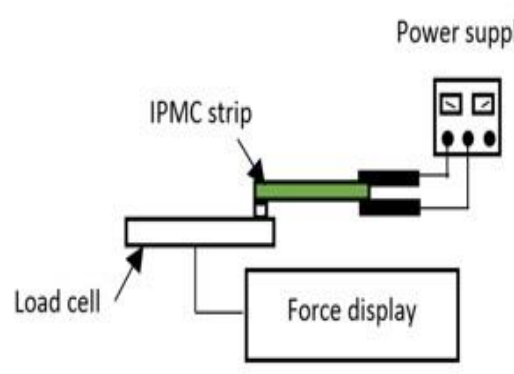

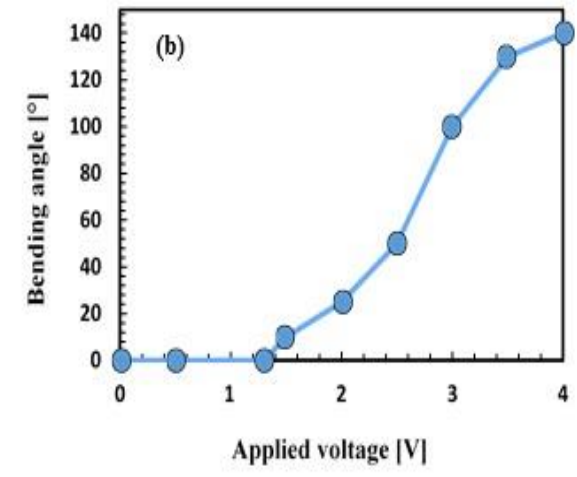

(b)

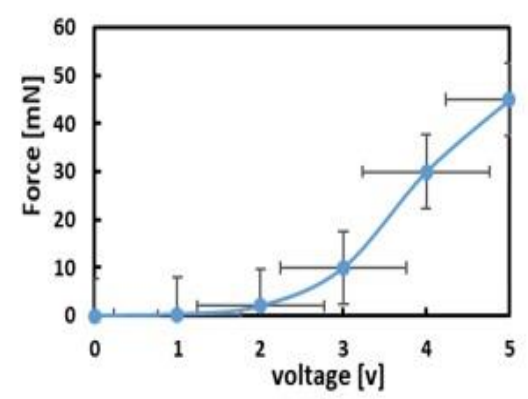

Figure $6 \mathrm{~b}$ shows the measurement results. Observations revealed that, the IPMC can make a force of $45 \mathrm{mN}$ in an applied electrical field of $5 \mathrm{~V}$. This makes our prepared IPMC a suitable leverage to make small forces in biomedical devices.

\section{Conclusion}

In this research study, IPMC was prepared using the optimized CEP process by using a bath ultra-sonication in the Pt ion deposition step. The extra reductant materials including amine groups were also removed from the reduction step to minimize the time and expense of the process. Microstructure analysis of the IPMC revealed that the optimized CEP method fabricated efficient electrodes suitable for actuating applications with a smooth and monotone platinum deposition. ICP spectroscopy was also utilized to determine the concentration of the Pt ions deposited on the nafion sheet in bath ultra- sonication step. The results revealed that, only $2.6 \%$ of the Pt ions were not deposited on the nafion sheet according to instrumentation or human error. Voltage angle and force voltage curves were also in good consistency with each other, showing the remarkable actuation properties of the fabricated IPMC.

\section{Acknowledgment}

The authors are grateful for the financial support from Iran University of Science and Technology and Tehran University.

\section{Disclosure statement}

No potential conflict of interest was reported by the authors.

\section{ORCID}

M. S. Saneei Mousavi (D): 0000-0003-1739-9540 


\section{References}

[1] M.S.S. Mousavi, A. Alaei, M. Hasani, M. Kolahdouz, F. Manteghi, F. Ataei, Mater. Res. Exp., 2018, 6, 35312-35321.

[2] V. Guarino, S. Zuppolini, A. Borriello, L. Ambrosio, Polymers, 2016, 8, 185.

[3] S. Chen, S. Yang, Z. Li, S. Xu, H. Yuan, S. Chen, Z. Ge, Polym. Compos., 2015, 36, 439-444.

[4] Y.C. Chou., P.C. Lee, T.F. Hsu, W.Y. Huang, L. Zi-Han, C.Y. Chuang, T.I. Yang, J.M. Yeh, Polym. Compos., 2014, 35, 617-625.

[5] M. Shahinpoor, K.J. Kim, D.J. Leo, Polym. Compos., 2003, 24, 24-33.

[6] J. Wang, A. McDaid, R. Sharma, K. Aw, Actuators, 2015, 4, 114-126.

[7] K.O. Federico Carpi, E. Smela, K. Asaka, IPMC Actuators: Fundamentals, Biomedical Applications of Electroactive Polymers, John Willey \& Sons: New Jeresy, 2009, pp 101-119.

[8] C.H. Jo, H.E. Naguib, R.H. Kwon, Adv. Sci. Technol., 2008, 54, 82-89.

[9] J. Wang, K.C. Aw, R. Sharma, Nano/Micro Eng. Mol. Syst. IEEE-NEMS; 2014, 1, 86-88.

[10] R. Dong, X. Tan, Smart Mater. Struct., 2012, 21, 065014.

[11] A. Punning, M. Kruusmaa, A. Aabloo, Sensors Actuat. A Physical., 2007, 133, 200-209.

[12] G.H. Feng, K.M. Liu, Sensors, 2014, 14, 8380-8397.

[13] E. Esmaeli, M. Ganjian, H. Rastegar, M. Kolahdouz, Z. Kolahdouz, G.Q. Zhang, Sensors Actuat. B Chem., 2017, 247, 498504.

[14] B. Bhandari, G.Y. Lee, S.H. Ahn, Int. J. Precis. Eng. Manuf., 2012, 13, 141-163.

[15] M. Shahinpoor, K.J. Kim, Smart Mater. Struct., 2004, 13, 1362-1388.
[16] Y. Bar-Cohen, Smart Struct. Mater., 2000, 3987, 140-146.

[17] M. porfiri Matteo Aureli, V. Kopman, IEEE/ASME Trans. Mechatron., 2010, 15, 603-614.

[18] M.S. Saneei Mousavi, A.H. Karami, M. Ghasemnejad, M. Kolahdouz, F. Manteghi, F. Ataei, J. Mech. Behav. Biomed. Mater., 2018, 86, 250-256.

[19] O.K. Asaka, K. Oguro, Chem Eng., 2001, 46, 764-768.

[20] G. Kim, H. Kim, I.J. Kim, J.R. Kim, J.I. Lee, M. Ree, J. Biomater. Sci. Polym. Ed., 2009, 20, 1687-1707.

[21] B.J. Liu, L.N. Ma, J. Su, W.W. Jing, M.J. Wei, X.Z. Sha, J. Biomed. Mater. Res. Part A; 2014, 102, 2055-2060.

[22] M. Shahinpoor, K.J. Kim, Smart Mater. Struct., 2001, 10, 819-833.

[23] F. Beigi, M.S.S. Mousavi, F. Manteghi, M. Kolahdouz, Appl. Clay Sci., 2018, 166, 131136.

[24] S. Nemat-nasser, C.W. Thomas, Ionomeric polymer-metal composites, University of California: San Diego, 2001, chapter 6.

[25] M. Hasani, A. Alaei, M.S.S Mousavi, E. Esmaeili, M. Kolahdouz, V. Naeini, M. Masnadi J. Micromechan. Microeng., 2019, 29, 1-21.

[26] P. Millet, F. Andolfatto, R. Durand, J. Appl. Electrochem., 1995, 25, 227-232.

[27] V. Palmre, S.J. Kim, D. Pugal, K. Kim, Int. J. Smart Nano Mater., 2014, 5, 99-113.

[28] Y. Wang, Z. Zhu, J. Liu, L. Chang, and H. Chen, Smart Mater. Struct., 2016, 25, 85012.

[29] H. Rasouli, L. Naji, M.G. Hosseini, RSC Adv., 2017, 7, 3190-3203.

[30] M. Safari, L. Naji, R.T. Baker, F.A. Taromi, Polymer, 2015, 76, 140-149.

How to cite this manuscript: Matin Sadat Saneei Mousavi, Faranak Manteghi, Mohammadreza Kolahdouz, Optimization of Ionic Polymer Metal Composite Fabrication via Chemical Electroless Plating Method; Actuation Application Study, Adv. J. Chem. A, 2020, 3(4), 454-461.

Copyright (C) 2020 by SPC (Sami Publishing Company)+ is an open access article distributed under the Creative Commons Attribution License, which permits unrestricted use, distribution, and reproduction in any medium, provided the original work is properly cited. 